\title{
Papel das ações transversais no FNDCT: redirecionamento, redistribuição, indução ou nenhuma das alternativas?*
}

\author{
Paulo A. Meyer M. Nascimento
}

Instituto de Pesquisa Econômica Aplicada (Ipea)

João Maria de Oliveira

Instituto de Pesquisa Econômica Aplicada (Ipea)

\section{RESUMO}

O presente trabalho analisa o papel das ações transversais na aplicação de recursos dos Fundos Setoriais de Ciência e Tecnologia (CTs), bem como na indução ao financiamento privado a pesquisa, desenvolvimento e inovação. Contrapondo-se à justificativa declarada para sua introdução, as ações transversais têm se mostrado, na prática, muito mais um instrumento de pulverização dos recursos dos fundos setoriais do que de efetivação de políticas estratégicas. Pelo menos isto é o que pode ser observado quando são confrontados os projetos apoiados e a realocação de recursos engendrada pelas açôes transversais com os temas, as áreas e os setores estratégicos estabelecidos pelos documentos oficiais de política. Os dados disponíveis sugerem que tais ações não proporcionaram, entre 2004 e 2008, nem um redirecionamento

* Os autores agradecem a colegas do Ipea e a dois pareceristas anônimos pelos comentários e sugestões ao presente trabalho. Eventuais erros e omissões remanescentes permanecem sendo de inteira responsabilidade dos autores. 
dos recursos a temas estratégicos não contemplados por CTs específicos, nem a redistribuição dos recursos entre os CTs existentes, nem uma maior indução à participação de empresas nos projetos apoiados.

Palavras-Chave | Ações Transversais; Fundos Setoriais; FNDCT; Políticas de CT\&I.

Códigos JEL | O38; L52.

\section{The new dynamics of the Brazilian sectorial funds after the introduction of transversal calls}

\section{ABSTRACT}

This paper analyses the role played by the so-called "transversal calls" on the sectorial funds' resource re-allocation, as well as on the attraction of private funding and participation in the supported proposals. In particular, we examine whether they have: i) redirected financial resources towards strategic topics not furthered by a specific sectorial fund; ii) redistributed monies among existing sectorial funds; iii) increased the participation of firms in the approved proposals. We refer to official documents to identify strategic topics, fields and economic sectors and check whether or not transversal calls benefited them in terms of resource allocation. Private sector involvement is evaluated through firms' participation in approved proposals and by the amount of financial resources engaged on them. Results suggest that none of the pointed targets seems to be accomplished between 2004 and 2008 - and indicate that Brazilian public ST\&I funding have been rather pulverised than rationalised in this period.

KEYwORDS | Transversal Calls; Brazilian Sectorial Funds; FNDCT; ST\&I Policies.

JEL-Codes | O38; L52. 


\section{Introdução}

A partir da criação do CT-Petro pela chamada Lei do Petróleo (Lei no 9.478/1997), a vinculação de receitas a fundos setoriais de Ciência e Tecnologia (hoje em número de 16) permitiu o revigoramento do Fundo Nacional de Desenvolvimento Científico e Tecnológico (FNDCT) ${ }^{1}$ e a perenidade da aplicação de recursos públicos no fomento a Pesquisa, Desenvolvimento e Inovação (PD\&I) no Brasil. Indo mais além, João Alberto De Negri (Ipea) e Mauro Borges Lemos (Cedeplar/UFMG) chegam a referir-se aos fundos setoriais como "o instrumento hoje disponível mais eficaz de fomento público ao financiamento privado em P\&D” (DE NEGRI; LEMOS, 2009, p.7).

A governança dos fundos setoriais tal como é atualmente, contudo, advém desde 2004. Em julho daquele ano, por entender que o conjunto dos fundos setoriais carecia de organicidade, uniformidade e coordenação, o governo federal reformulou seu modus operandi. No bojo dessas mudanças surgiram as açôes transversais.

Apesar de serem financiadas com um mínimo de 50\% das receitas vinculadas aos fundos setoriais que compõem o FNDCT, essas ações ainda não foram objeto de estudos mais detalhados. ${ }^{2}$ Assim, o presente trabalho representa uma abordagem inédita dessa questão, ao se propor a identificar a direção que o fomento público a PD\&I tomou no Brasil após o advento das ações transversais em 2004.

Isto será feito a partir da investigação de três hipóteses:

- hipótese 1 (ou hipótese do redirecionamento) - As ações transversais vêm sendo utilizadas para fomentar temas estratégicos que não se relacionam diretamente a nenhum setor que já disponha de fundo específico;

- hipótese 2 (ou hipótese da redistribuição) - As ações transversais vêm sendo utilizadas para fortalecer o apoio a setores estratégicos cujos fundos próprios podem não ser suficientes isoladamente para dar o impulso necessário à PD\&I naquele setor;

1 O FNDCT foi instituído pelo Decreto-Lei n. 719/1969, restabelecido posteriormente pela Lei n. 8.172/1991, modificado pela Lei n. 10.197/2001 e regulamentado pela Lei n. 11.540/2007. Foi constituído para servir de principal instrumento de apoio financeiro ao desenvolvimento científico e tecnológico. Para mais detalhes acerca do FNDCT e de sua evolução histórica, ver Ferrari (2002), Pacheco (2007), Melo (2009) e Longo e Derenusson (2009).

2 Durante a preparação do presente texto só foi encontrado um trabalho precedente que buscava apresentar alguma análise de resultados das ações transversais, embora sem investigá-las a fundo em separado. Trata-se de um relatório sobre os fundos setoriais elaborado em 2005/2006 para o Centro de Gestão e Estudos Estratégicos (CGEE) por Pereira, Hasegawa e Azevedo (2006). Nele é feito um estudo de aderência dos projetos apoiados pela FINEP via CTs e das ações transversais até 2005. As diferenças metodológicas e de resultados entre este e aquele trabalhos serão exploradas na seção 4. 
- hipótese 3 (ou hipótese da indução) - As ações transversais seriam, no âmbito dos fundos setoriais, o principal meio pelo qual o governo induziria o financiamento privado a PD\&I.

A hipótese 1 foi chamada de hipótese do redirecionamento porque testa em que medida as ações transversais foram utilizadas para redirecionar os recursos do FNDCT a temas estratégicos que não estariam diretamente contemplados pelos fundos setoriais existentes. Já a hipótese 2 foi denominada hipótese da redistribuição porque examina se houve alguma tendência de se valer das ações transversais para fortalecer, por meio de transferências entre eles, fundos considerados estratégicos, cuja receita vinculada fosse porventura vista como insuficiente. Por fim, a hipótese 3, da indução, é assim designada porque investiga se as ações transversais teriam tido algum papel de estimular o financiamento privado a P,D\&I.

Essas três hipóteses são investigadas nas seções 4 e 5 . Antes disso, a seção 2 discorre sobre o contexto em que foram introduzidas as ações transversais e a seção 3 identifica os temas estratégicos nos documentos oficiais de política do período. $\mathrm{O}$ texto também coloca em discussão, na seção 6 , os mecanismos de operacionalização das ações transversais, isto é, as pistas que a utilização dos diferentes instrumentos convocatórios disponíveis fornece acerca da destinação efetivamente dada às ações transversais. Por fim, as consideraçôes finais e eventuais implicaçôes de política são expostas na seção 7 .

\section{Contexto geral das ações transversais}

As ações transversais foram introduzidas no âmbito dos fundos setoriais em 2004, após um diagnóstico de que, a despeito do sucesso dos diversos CTs na garantia de recursos vinculados para aplicação em Pesquisa, Desenvolvimento e Inovação (PD\&I) em setores estratégicos, as ações apoiadas ainda eram segmentadas e dispersas, careciam de prazos e procedimentos uniformes e de coordenação entre si, além de apresentarem problemas de eficiência na aplicação dos recursos e ainda pouca integração com as políticas então vigentes de desenvolvimento nacional (particularmente a Política Industrial, Tecnológica e de Comércio Exterior - PITCE). Esse diagnóstico subsidiou mudanças significativas na governança dos fundos setoriais já em 2004, em especial a criação do Comitê de Coordenação dos Fundos Setoriais (CCFS), a unificação dos calendários das reunióes dos comitês gestores de cada fundo e a instituição das ações transversais. ${ }^{3}$

3 Em discurso proferido em 18/05/2004, quando da primeira reunião dos comitês gestores dos fundos setoriais no governo Lula, o então ministro da Ciência e Tecnologia, Eduardo Campos, destacou que a ativação do CCFS visava 
Com essas modificações, um piso de $50 \%$ das receitas não contingenciadas de cada fundo passou a ser destinado a editais cujas temáticas não precisam necessariamente estar relacionadas ao setor do fundo que originariamente aplicaria os recursos. Cabe ressaltar, neste ponto, que tampouco anteriormente os temas das demandas ${ }^{4}$ estavam necessariamente subjugados a áreas diretamente relacionadas ao setor correspondente. Em verdade, o setor que dá nome ao fundo específico desde sempre remeteu apenas à fonte dos recursos, não à sua destinação. Em outras palavras, mesmo antes das modificaçôes de 2004, o nome de cada fundo setorial referia-se ao setor cuja arrecadação fiscal o financia, e não à área de concentração dos editais que lança. A exceção a isso eram os fundos de natureza eminentemente transversal, como o CT-Infra ou o CT-Verde e Amarelo, criados com recursos de outrem para finalidades específicas.

Diferentemente dos fundos setoriais, que dispunham cada qual de seu comitê gestor, as açôes transversais eram definidas no âmbito do CCFS, que foi criado como instância superior à dos comitês gestores e no qual a representação do poder público é majoritária e em maior proporção do que nos comitês gestores de cada fundo. Em tese, a definição dos temas das ações transversais se dá após discussão em fóruns apropriados e observando as diretrizes estratégicas dos documentos vigentes de políticas nacionais voltadas ao desenvolvimento industrial e tecnológico, para definir o conteúdo dos editais que financiariam as chamadas ações transversais.

Em verdade, as modificações que, entre outras coisas, criaram o CCFS e engendraram as ações transversais decorreram exclusivamente de atos administrativos, e assim permaneceram durante os três anos subsequentes. Em 2007, a promulgação da Lei n. 11.540 veio preencher um vácuo na normatização dessas e de outras regras. Em especial, esta lei detalha, em um único diploma legal, as receitas vinculadas ao FNDCT, inclusive aquelas até então previstas de maneira esparsa em cada uma das leis específicas a fundos setoriais, e institui formalmente as açōes transversais - isto é, formaliza legalmente o que já era prática havia três anos.

reduzir a fragmentação e a dispersão dos recursos dos fundos, cuja aplicação era, a seu ver, definida em estratégias estanques formuladas separadamente no âmbito de cada comitê gestor. Além disso, considerando a necessidade de seguir os eixos governamentais dados pela PITCE, em conjunto com a decisão política de privilegiar a inclusão social e a formação de um mercado de massas no Brasil, o ministro antecipou em seu discurso a criação das ações transversais, que viriam a ser instituídas pelo CCFS em julho do mesmo ano (cf. fatos narrados em notícia publicada em 20 de maio de 2004 no site <http://www.inovacao.unicamp.br/report/news-comites.shtml>, acesso em 05/11/2009).

4 O termo "demanda" aqui utilizado remete ao tipo de convocatória, podendo ser: chamada pública, encomenda ou carta-convite. 
Vale sempre destacar, contudo, que as ações transversais não formam um $\mathrm{CT}^{5}$ à parte. Caracteristicamente, os CTs continuam sendo geridos por seus respectivos comitês gestores, são regulados por legislação específica, dispõem de receitas vinculadas e seguem um plano de aplicação delineado por diretrizes estratégicas preestabelecidas.

Como o CCFS é formado apenas por representantes do governo, ${ }^{6}$ as ações transversais foram interpretadas pelos representantes do setor produtivo, dele ausentes, como sendo uma interferência indevida do governo nas deliberações acerca das aplicações dos recursos referentes aos fundos setoriais. $\mathrm{O}$ argumento principal das críticas às ações transversais ${ }^{7}$ era que esses recursos, oriundos de contribuições recolhidas junto a setores da iniciativa privada, deveriam priorizar a inovação tecnológica nas empresas. Talvez por conta dessas críticas, a partir de 2005, as ações transversais passaram a ser discutidas em fóruns dos quais participavam também os representantes do setor produtivo, ${ }^{8}$, antes de serem levadas ao CCFS.

As inovações na governança dos fundos setoriais introduzidas em 2004-2005 e as normas sancionadas em 2007 (na Lei n. 11.540) não interferiram na evolução dos desembolsos do FNDCT, mas alteraram a maneira como esses recursos são alocados. Diante da inexistência de diretrizes e critérios claros e objetivos a guiarem a formulação das demandas de ações transversais, dois pontos de vista antagônicos se firmaram à época para tentar antever de que forma as açôes transversais reorganizariam a dinâmica dos fundos setoriais.

Por um lado, é possível argumentar que a introdução das ações transversais prejudicaria o fortalecimento de setores estratégicos tal como delineados pelas políticas nacionais de desenvolvimento e contemplados por fundos específicos, gerando maior dispersão dos recursos. Por outro, as ações transversais poderiam constituir um importante instrumento de ajuste às próprias políticas de desenvolvimento

5 Os Fundos Setoriais de Ciência e Tecnologia costumam ser designados por uma sigla iniciada com CT e seguida de um acrônimo que remeta ao seu setor correspondente. A título de exemplo, CT-Petro é o Fundo Setorial de Petróleo e Gás Natural, CT-Hidro é o Fundo Setorial de Recursos Hídricos e CT-Info é o Fundo Setorial para Tecnologia da Informação. Assim, por CT entendam-se, no presente trabalho, os fundos setoriais propriamente ditos - ou seja, instrumentos de financiamento de projetos de pesquisa, desenvolvimento e inovação que disponham de receita vinculada, de legislação regulatória própria e que sigam um plano de aplicação guiado por diretrizes estratégicas preestabelecidas.

6 Integram o Comitê de Coordenação dos Fundos Setoriais (CCFS): o secretário-executivo do MCT (que o preside), os presidentes do CNPq e da Finep e os presidentes de cada um dos comitês gestores, estes também, em regra, vinculados ao MCT.

7 Vide, por exemplo, notícia publicada em 5 de agosto de 2004 no site <http://www.inovacao.unicamp.br/report/ news-acoestrans.shtml>, mantido pela Unicamp: "Ações transversais aprovadas pelo governo não agradam representantes do setor produtivo nos Comitês Gestores" (acesso em 20/10/2009).

8 Ver Rezende (2006, p. 351-352) para um relato do processo decisório que passou a ser estabelecido a partir de 2005 para a definição das temáticas que seriam objeto de demandas das ações transversais. 
que deveriam nortear a alocação de recursos dos fundos setoriais, uma vez que potencialmente permitiriam tanto incorporar ações estratégicas que não estariam sendo fomentadas no âmbito de setores específicos, quanto reforçar o apoio a setores estratégicos cujos fundos próprios não fossem suficientes isoladamente para dar o impulso necessário à PD\&I naquele setor.

Esses argumentos antagônicos constituem o cerne das duas primeiras hipóteses a serem investigadas: a do redirecionamento; e a da redistribuição.

A princípio, confirmando-se essas hipóteses, o desempenho das ações transversais estaria compatível com a justificativa para sua introdução. Caso ambas sejam rejeitadas, o cenário estaria mais próximo daquele delineado por seus críticos. Sua investigação, entrementes, exige estabelecer a priori que tipos de demanda poderiam ser considerados "estratégicos" e que parâmetros podem ser usados para testá-las a partir dos dados disponíveis, levando a conduzir a análise ligeiramente diferente do padrão adotado para o estudo vertical dos fundos setoriais propriamente ditos.

\section{Temas estratégicos no âmbito das ações transversais}

Conforme discutido anteriormente, não há um documento formal estabelecendo diretrizes estratégicas para as ações transversais. Tampouco há uma lei específica regulamentando-as. O único diploma legal que define, de modo abrangente, o escopo das açōes transversais é a lei que regulamenta o FNDCT (Lei n. 11.540/2007), promulgada três anos após a própria instituição das ações transversais. $\mathrm{O}$ artigo 14 (caput e $\$ 1^{\circ}$ ) da lei em questão dispóe que:

Art. 14. Os recursos do FNDCT poderão financiar as ações transversais, identificadas com as diretrizes da Politica Nacional de Ciência, Tecnologia e Inovação e com as prioridades da Política Industrial e Tecnológica Nacional.

S $1^{\circ}$ Para efeito do disposto no caput deste artigo, consideram-se açôes transversais aquelas que, relacionadas com a finalidade geral do FNDCT, são financiadas por recursos de mais de um Fundo Setorial, não necessitando estar vinculadas à destinação setorial especifica prevista em lei.

Afora esse texto legal, outra potencial fonte para clarificar em alguma medida os propósitos, objetivos e estratégias das ações transversais é um artigo escrito pelo então ministro da Ciência e Tecnologia, Sergio Machado Rezende (2006, p. 351), no qual é argumentado que: 
As Açôes Transversais foram implementadas com o objetivo de possibilitar a utilização de recursos de diversos fundos para suportar iniciativas mais abrangentes do que aquelas de caráter setorial. Elas são financiadas com recursos dos fundos de caráter transversal (Infra - Estrutura e Verde - Amarelo) ou com recursos de mais de um Fundo Setorial. Orientam-se pelos eixos estratégicos do MCT e podem ser executadas através de chamadas públicas para seleção de projetos, ou através de encomendas a grupos de pesquisa elou suas redes e instituiçôes de pesquisa.

Depreende-se, então, que as ações transversais seriam as demandas financiadas com recursos de mais de um fundo setorial, sem obrigatoriedade de ater-se a temáticas de setores específicos, e cujas diretrizes estratégicas são as prioridades da política industrial e tecnológica nacional que sejam compatíveis com a política nacional de CT\&I em vigência.

A própria base fornecida pelo Ministério da Ciência e Tecnologia (MCT) ao Instituto de Pesquisa Econômica Aplicada (Ipea), contendo informaçôes sobre projetos apoiados por todos os fundos setoriais, classifica-os em categorias definidas a partir dos eixos e linhas de ação do plano nacional de CT\&I vigente. A distribuição do valor contratado por categoria encontra-se no Gráfico 1.

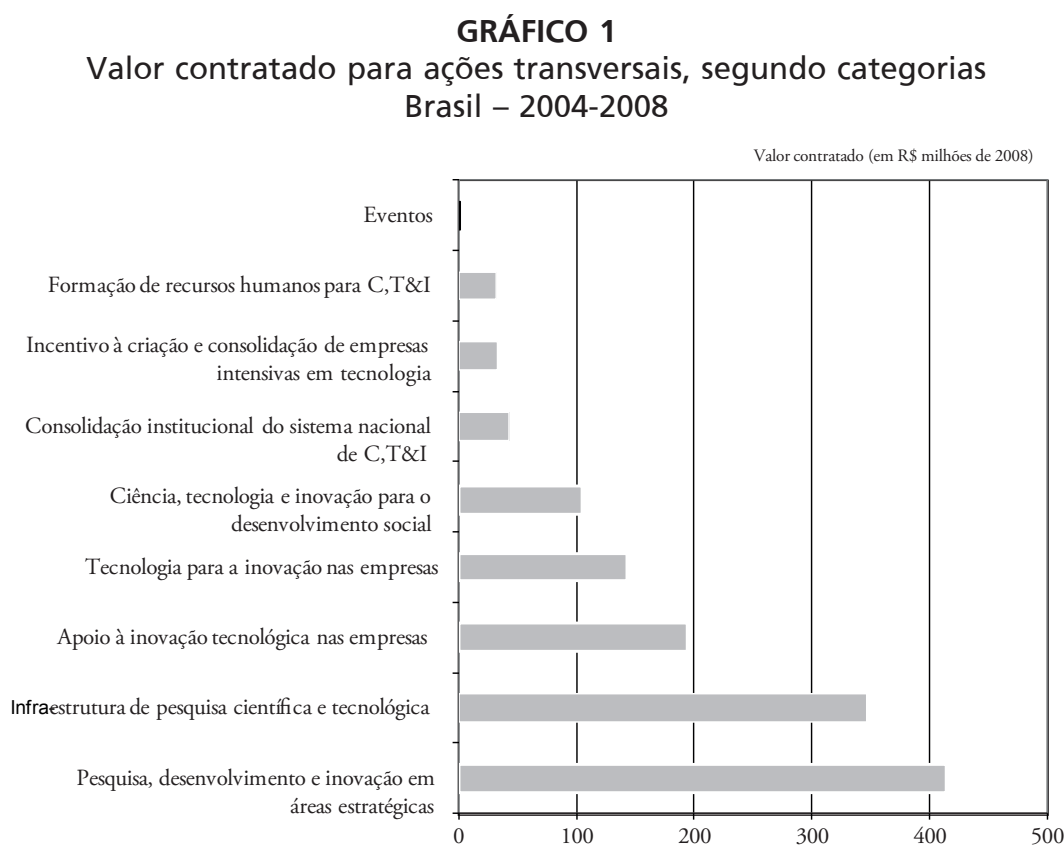

Fonte: Ministério da Ciência e Tecnologia - MCT. Elaboração dos autores. 
Nota-se que a categoria "PD\&I em áreas estratégicas" consumiu a maior parte dos recursos aplicados em ações transversais entre 2004 e 2008 - algo em torno de R \$ 414 milhões, ou 31,6\% dos R \$1,31 bilhão contratados até setembro de 2008. ${ }^{9}$

As áreas consideradas estratégicas pela Política Nacional de Ciência, Tecnologia e Inovação - PNCTI 2007-2010 são: biotecnologia; nanotecnologia; TIC; insumos para a saúde; biocombustíveis; energia elétrica; hidrogênio e energias renováveis; petróleo; gás e carvão mineral; agronegócio; biodiversidade e recursos naturais; Amazônia e semiárido; meteorologia e mudanças climáticas; programa espacial; programa nuclear; e defesa nacional e segurança pública. Essas áreas contemplam aquelas apontadas pela PNCTI 2003-2006 e acrescentam outras, englobando, ainda, as prioridades da política industrial e tecnológica pertinente.

Seguindo a interpretação dada anteriormente ao artigo 14 da Lei n. 11.540/2007, as açôes transversais serão analisadas segundo sua aderência à política industrial e tecnológica nacional pertinente ao período de julho de 2004 (quando foram lançadas as primeiras chamadas públicas para ações transversais) a setembro de 2008 (limite do recorte dos projetos contidos na base para a análise).

\subsection{A PITCE como diretriz para análise das ações transversais de 2004 a 2008}

A Política Industrial, Tecnológica e de Comércio Exterior (PITCE), lançada em 31 de março de $2004^{10}$ e efetiva até meados de 2008, quando foi lançada a Política de Desenvolvimento Produtivo (PDP), guiou a política industrial do governo federal no período a que se aplica a presente análise.

A PITCE parte de cinco linhas de ação, ${ }^{11}$ que se desdobram em 57 medidas. Destas, 23 tinham, entre os executores responsáveis, o MCT ou alguma agência a ele vinculado. Considerando-se que as ações transversais são definidas no âmbito do CCFS e executadas via Financiadora de Estudos e Projetos (Finep) ou Conselho Nacional de Desenvolvimento Científico e Tecnológico (CNPq), foram examinadas as medidas da PITCE a cargo dessas duas agências.

Esse procedimento permitiu a identificação, na terminologia adotada nos documentos da PITCE, de cinco áreas prioritárias, quatro opções estratégicas

9 Quantia aproximada a partir de valores anuais deflacionados pelo IPCA (ano-base 2008). Todos os recursos analisados foram atualizados a valores de 2008 utilizando-se o IPCA.

10 As diretrizes da PITCE já haviam sido publicadas em 26 de novembro de 2003, mas suas medidas e metas só foram efetivamente divulgadas quando do seu lançamento, em 31 de março de 2004.

11 São elas: inovação e desenvolvimento tecnológico; inserção externa; modernização industrial; capacidade e escala produtiva; e opções estratégicas. 
e quatro programas, que, em suma, ensejam considerar 11 temas potenciais de demandas das ações transversais, se estas tiverem sido, de fato, pautadas pela Política no período em análise: biotecnologia (que já dispõe de um fundo setorial próprio); biodiesel; biomassa; nanotecnologia; TIC/semicondutores; TIC/software; fármacos e medicamentos; Tecnologia Industrial Básica (TIB); formação de recursos humanos em microeletrônica; Arranjos Produtivos Locais (APL); e modernização de institutos e centros de pesquisa.

Assim, a hipótese 1 (do redirecionamento) será testada a partir da aderência dos projetos aos temas listados, enquanto a hipótese 2 (da redistribuição) será testada verificando se houve algum remanejamento significativo de recursos entre os fundos setoriais existentes mediado pelas ações transversais.

\section{Investigando as hipóteses do redirecionamento e da redistribuição}

\subsection{Aderência dos projetos a temas estratégicos da PITCE}

Para verificar seu grau de aderência aos 11 temas levantados como prioritários na PITCE, foram examinados os títulos, resumos e palavras-chave dos projetos contemplados pelas ações transversais. Aqueles que sinalizavam ter por objeto a exploração de algum desses temas foram então contabilizados como "aderentes", enquanto os que não puderam ser associados a nenhum deles, ou que consistiam somente em eventos, foram então classificados como "não aderentes".

Em avaliação anterior dos fundos setoriais, Pereira, Hasegawa e Azevedo $(2006)^{12}$ buscaram qualificar o índice de aderência temática estimada para cada um dos fundos setoriais com o uso da seguinte escala:

- $\quad$ índice de aderência alto: > 95\%;

- $\quad$ índice de aderência médio: < 95-80\% >;

- $\quad$ índice de aderência baixo: $<80 \%$.

Essa escala não se estendeu, entretanto, à análise das ações transversais no referido estudo, pois, nas palavras dos autores, em se tratando de ações transversais (ATs):

na maioria dos casos, o fundo que mais concedeu recursos ao projeto não tinha relação com a área de pesquisa do mesmo, o que ocasionaria um indice de aderência das ATs muito baixo,

12 A avaliação de Pereira, Hasegawa e Azevedo (2006) englobava "todos os projetos de todas as ações FINEP lançadas entre 2001 e 2005 em atenção à Política de Fundos Setoriais" (ob. Cit., p. 11). 
uma vez que os projetos eram financiados por diversos fundos e que, muitas vezes, demonstravam aderência temática a um fundo que concedeu recursos mas que não era o principal financiador, considerou-se que não seria adequado classificar o projeto como não aderente uma vez que mantinha aderência com as áreas temáticas de pelo menos um dos fundos financiadores. (PEREIRA; HASEGAWA; AZEVEDO, 2006, p. 34)

No presente trabalho, contudo, optou-se por adotar essa escala para averiguar o nível de aderência dos projetos aos temas estratégicos da PITCE e, por conseguinte, testar a hipótese do redirecionamento. A estratégia e até mesmo a interpretação aqui adotadas diferem daquela de Pereira, Hasegawa e Azevedo (2006), tendo em vista que não partem do pressuposto de que os projetos apoiados por ações transversais tenham necessariamente alguma aderência a pelo menos um dos fundos (isto será verificado apenas quando for testada a hipótese da redistribuição). Pelo contrário, a própria hipótese 1 ora examinada decorre do objetivo, tornado público desde 2004 e instituído por lei em 2007, de direcionar as ações transversais a temas estratégicos da política nacional vigente, ainda que tais temas não sejam contemplados por um fundo específico.

Feitas essas ponderações, a análise procedida no presente trabalho levou a um índice de aderência de 27,4\% aos 11 temas estratégicos da PITCE (Tabela 1).

Utilizando como parâmetro a escala arbitrada por Pereira, Hasegawa e Azevedo (2006) para os fundos específicos, tem-se que os projetos apoiados por ações transversais entre julho de 2004 e setembro de 2008 tiveram, em termos de valores contratados, baixa aderência à PITCE. Assim, não se confirma a hipótese 1 (do redirecionamento), isto é, não foi encontrada evidência empírica suficientemente robusta de que as ações transversais estariam sendo utilizadas para fomentar temas estratégicos sem relação direta com setores contemplados com fundos específicos.

Não obstante, verificando-se a distribuição dos 27,4\% dos recursos contratados que tiveram aderência a algum dos onze temas estratégicos da PITCE, conclui-se que nanotecnologia, ${ }^{13}$ modernização de institutos de pesquisa, biotecnologia e TICl software foram, em alguma medida, priorizados, enquanto APL, tecnologia industrial básica e formação de recursos humanos em microeletrônica foram quase que totalmente esquecidos.

13 Sobre projetos relacionados à nanotecnologia que tenham sido apoiados pelos fundos setoriais desde 2000 até setembro de 2008, ver César Jr. (2010). 
TABELA 1

Grau de aderência dos projetos financiados aos temas estratégicos da PITCE Brasil - 2004-2008

\begin{tabular}{|c|c|c|c|}
\hline $\begin{array}{l}\text { Tema estratégico } \\
\text { na PITCE }\end{array}$ & $\begin{array}{c}\text { Termos de } \\
\text { identificação (1) }\end{array}$ & $\begin{array}{c}\text { \% do total } \\
\text { contratado } \\
\text { identificado } \\
\text { como aderente }\end{array}$ & $\begin{array}{l}\% \text { do total } \\
\text { aderente }\end{array}$ \\
\hline Nanotecnologia & Nano & 6,5 & 23,8 \\
\hline $\begin{array}{l}\text { Modernização de } \\
\text { institutos e centros } \\
\text { de P\&D }\end{array}$ & $\begin{array}{l}\text { Ampliação \& laboratório, } \\
\text { instalação \& laboratório, } \\
\text { modernização \& pesquisa, } \\
\text { investimento \& tecnologico }\end{array}$ & 5,3 & 19,4 \\
\hline Biotecnologia & Biotecnologia & 4,1 & 14,9 \\
\hline $\begin{array}{l}\text { Fármacos e } \\
\text { medicamentos }\end{array}$ & $\begin{array}{l}\text { Medicamento, fármaco, cicatriza- } \\
\text { ção, medicinal, tratamento, vacina }\end{array}$ & 3,1 & 11,3 \\
\hline TIC/software & Software & 3 & 11,1 \\
\hline Biodiesel & Biodiesel & 2,2 & 8,1 \\
\hline Biomassa & Biomassa, bioenergia & 1,8 & 6,5 \\
\hline TIC/semicondutores & $\begin{array}{l}\text { Semicondutor, componente \& } \\
\text { eletrônico }\end{array}$ & 0,6 & 2,1 \\
\hline TIB & Indústria básica & 0,4 & 1,4 \\
\hline $\begin{array}{l}\mathrm{RH} \text { em } \\
\text { microeletrônica }\end{array}$ & $\begin{array}{l}\text { Recursos humanos \& } \\
\text { microeletronica, formação \& } \\
\text { microeletrônica }\end{array}$ & 0,3 & 1,1 \\
\hline APL & $\begin{array}{l}\text { Arranjo produtivo, APL, cadeia } \\
\text { produtiva }\end{array}$ & 0,1 & 0,3 \\
\hline Total & & 27,4 & 100 \\
\hline
\end{tabular}

Fonte: Ministério da Ciência e Tecnologia - MCT. Elaboração dos autores.

(1) Termos buscados no título, resumo e palavras-chave dos projetos, como forma de filtragem inicial de sua aderência aos temas estratégicos. Em seguida foram excluídos os projetos cujo objeto era a organização de eventos, bem como aqueles que, mesmo mencionando os termos de busca, não tinham relação direta com o desenvolvimento ou aplicação dos temas estratégicos.

\subsection{Aderência dos projetos a temáticas de fundos setoriais existentes}

Procedendo-se de forma semelhante à da seção anterior, foram identificados os projetos aderentes aos fundos setoriais específicos. Com isso, buscou-se averiguar se tem havido transferência de recursos entre fundos, por meio das ações transversais - e, assim, testar a hipótese 2 (da redistribuição). Tal como já havia sido 
observado por Pereira, Hasegawa e Azevedo (2006), uma análise de aderência aos CTs dos projetos apoiados pelas ações transversais não poderia ser pautada no volume de recursos destinado por cada CT à ação. Conforme visto, e em consonância com os motivos arguidos para criá-las, isto deve-se ao fato de que as ações transversais teriam por escopo iniciativas mais abrangentes e não necessariamente relacionadas a setores já atendidos por CTs.

Os resultados encontrados, bem como o método de identificação dos projetos aderentes aos fundos setoriais propriamente ditos, são apresentados na Tabela 2 .

Como se vê na Tabela 2, chegou-se a um índice de aderência de 27,2\% do valor contratado por ações transversais aos fundos setoriais específicos. Portanto, a evidência empírica levantada tampouco corrobora a hipótese da redistribuição, o que significaria dizer que as ações transversais não estariam realocando significativamente os recursos entre os fundos setoriais.

Ainda assim, uma análise mais apurada dos $27,2 \%$ de recursos realocados permite identificar melhor quais fundos teriam sido receptores líquidos de recursos do FNDCT, após o remanejamento feito pelas ações transversais. Os setores de agronegócio (15,7\%), energia $(15,3 \%)$ e biotecnologia $(15,1 \%)$ foram contemplados com quase metade dos recursos realocados internamente entre os fundos via açôes transversais.

À primeira vista, o CT-Agronegócio, o CT-Energia e o CT-Biotecnologia foram os mais beneficiados pelo advento das ações transversais. Contudo, nem mesmo esses três fundos aparecem como receptores líquidos na redistribuição de recursos proporcionada por elas. ${ }^{14}$ Isto porque, entre 2005 e 2008, os 50\% da arrecadação vinculada ao CT-Agronegócio, CT-Energia e CT-Biotecnologia permitiram a contratação, respectivamente, de $\mathrm{R} \$$ 53,8 milhões, $\mathrm{R} \$ 127,9$ milhões e R \$ 43,6 milhões, enquanto projetos contratados nesses setores por demandas de ações transversais no mesmo período consumiram apenas $\mathrm{R} \$$ 45,8 milhões, $\mathrm{R} \$$ 44,6 milhões e R $\$ 44$ milhões, respectivamente. A Tabela 3 mostra o saldo líquido de cada fundo setorial entre 2005 e $2008 .^{15}$

14 Vale ressaltar, porém, que as ações transversais superaram o CT-Agronegócio em quase 20\%, no que tange à aplicação de recursos em projetos aderentes à temática agrícola. Este resultado foi encontrado por Vieira Filho (2010), ao investigar o percentual de participação, nas ações transversais e no CT-Agronegócio, dos projetos relacionados à temática agrícola. No presente trabalho, contudo, não foram aplicados quaisquer filtros aos projetos do CT-Agronegócio. Para fins de análise, considera-se suficiente o pressuposto de que os projetos apoiados por cada fundo setorial específico sejam aderentes ao setor que dá nome ao próprio fundo.

15 A Tabela 3 considerou apenas as transferências a partir de 2005 porque as ações transversais foram criadas em julho de 2004. Já tendo transcorrido sete meses do ano quando houve a criação do CCFS e das ações transversais, tornar-se-ia difícil uma comparação com os anos seguintes, cujos valores contratados eram distribuídos por todos os doze meses do ano, e não apenas a cinco. Daí a decisão de não incluir os valores referentes a 2004 no cálculo das transferências inter-CTs ocasionadas pelas ações transversais. 
TABELA 2

Grau de aderência de projetos a fundos setoriais já existentes Brasil - 2004-2008

\begin{tabular}{|c|c|c|c|}
\hline $\mathrm{CT}$ & Termos de identificação (1) & $\begin{array}{l}\% \text { do total } \\
\text { contratado } \\
\text { identificado } \\
\text { como } \\
\text { aderente }\end{array}$ & $\begin{array}{l}\% \text { do total } \\
\text { aderente }\end{array}$ \\
\hline Agronegócio & $\begin{array}{l}\text { Agronegócio, agroindustria, irrigação, } \\
\text { agrotóxico, fertilização, agricultura, } \\
\text { agropecuária }\end{array}$ & 4,3 & 15,7 \\
\hline Energia & $\begin{array}{l}\text { Energia, energético, energética, } \\
\text { elétrica, eólica }\end{array}$ & 4,2 & 15,3 \\
\hline Biotecnologia & Biotecnologia, biotecnológico & 4,1 & 15,1 \\
\hline Infraestrutura & $\begin{array}{l}\text { Drenagem, infra, urbano, tratamento } \\
\text { de água, poluição, cidade }\end{array}$ & 3 & 11,2 \\
\hline Info & $\begin{array}{l}\text { Informática, software, tecnologia } \\
\text { da informação, computa, hardware, } \\
\text { sistemas, mineração de dados }\end{array}$ & 2,3 & 8,6 \\
\hline Petróleo & $\begin{array}{l}\text { Petróleo, gás natural, petroquímica, } \\
\text { betume, GNV }\end{array}$ & 2 & 7,4 \\
\hline Saúde & $\begin{array}{l}\text { Fármaco, saúde, biologia, medicina, } \\
\text { médica, doença, diagnóstico }\end{array}$ & 1,7 & 6,1 \\
\hline Amazônia & Amazônia, amazonas, amazônica & 1,4 & 5,3 \\
\hline Hidro & Hidrologia, hidrográfica, hídrico & 0,9 & 3,3 \\
\hline Transportes & Transporte, logística, modal & 0,6 & 2,1 \\
\hline Mineral & Mineração, mineral, & 0,4 & 1,5 \\
\hline Aquaviário & Aquaviário, naval & 0,2 & 0,8 \\
\hline Espacial & Espacial, estelar, astronomia & 0 & 0,1 \\
\hline Funttel & $\begin{array}{l}\text { Telecomunicação, comunicação, } \\
\text { telefonia, televisão, móbile, TV, sem fio }\end{array}$ & 2,1 & 7,7 \\
\hline Total & & 27,2 & 100,0 \\
\hline
\end{tabular}

Fonte: Ministério da Ciência e Tecnologia - MCT. Elaboração dos autores.

(1) Termos buscados no título, resumo e palavras-chave dos projetos, como forma de filtragem inicial de sua aderência aos fundos setoriais já existentes. Em seguida foram excluídos os projetos cujo objeto era a organização de eventos, bem como aqueles que, mesmo mencionando os termos de busca, não tinham relação direta com o desenvolvimento ou aplicação dos temas atinentes aos fundos.

Nota: O CT Verde-Amarelo, por sua natureza transversal, não foi considerado na análise de aderência de que trata esta tabela. Os CT-Amazônia e CT-Infra, embora também de natureza transversal, foram incluídos por disporem de uma temática (infraestrutura de pesquisa) e regiāo (Amazônia) capazes de identificar mais facilmente projetos a eles aderentes. O CT-Aeronáutico, embora vertical, não aparece na presente tabela porque não foram identificados projetos que lhe fossem potencialmente aderentes. 
TABELA 3

Recursos contratados pelos fundos setoriais, recursos contratados pelas ações transversais em projetos aderentes a fundos específicos e o saldo líquido de cada fundo após as transferências para e a partir das ações transversais

Brasil - 2005-2008

\begin{tabular}{|c|c|c|c|}
\hline $\mathrm{CT}$ & $\begin{array}{c}\text { Valor contratado } \\
\text { (R\$ milhões) pelo } \\
\text { CT } \\
(\mathrm{a})\end{array}$ & $\begin{array}{c}\text { Valor contratado } \\
\text { (R\$ milhões) pelas } \\
\text { ATs em temáticas } \\
\text { aderentes ao CT } \\
\text { (b) }\end{array}$ & $\begin{array}{l}\text { Saldo líquido do } \\
\text { CT em relação às } \\
\text { ATs } \\
\text { (b)-(a) }\end{array}$ \\
\hline CT-Aeronáutico & 67,60 & (1) & $-67,60$ \\
\hline CT-Agronegócio & 53,80 & 45,78 & $-8,02$ \\
\hline CT-Amazônia & 35,12 & 15,45 & $-19,66$ \\
\hline CT-Aquaviário & 31,61 & 2,33 & $-29,28$ \\
\hline CT-Biotecnologia & 43,57 & 44,03 & 0,46 \\
\hline CT-Energia & 127,88 & 44,61 & $-83,26$ \\
\hline CT-Espacial & 0,50 & 0,29 & $-0,21$ \\
\hline CT-Hidro & 67,82 & 9,62 & $-58,20$ \\
\hline CT-Info & 53,80 & 25,08 & $-28,72$ \\
\hline CT-Infra & 689,95 & 32,66 & $-657,29$ \\
\hline CT-Mineral & 22,96 & 4,37 & $-18,59$ \\
\hline CT-Petróleo & 209,05 & 21,58 & $-187,47$ \\
\hline CT-Saúde & 44,34 & 17,79 & $-26,55$ \\
\hline CT-Transporte & (1) & 6,12 & 6,12 \\
\hline Funtel & (1) & 22,45 & 22,45 \\
\hline Verde e Amarelo & 56,85 & (1) & $-56,85$ \\
\hline
\end{tabular}

Fonte: Ministério da Ciência e Tecnologia - MCT. Elaboração dos autores.

(1) Valor igual a R \$ 0,00 ou não se aplica. No caso do CT-Aeronáutico, não foram identificados projetos que lhe fossem aderentes nas açōes transversais. O CT-Transporte não contratou projetos entre 2005 e 2008. O Funttel contratou R \$ 83,3 milhōes entre 2005 e 2008, mas este é um fundo setorial que não compõe o FNDCT e, portanto, não transfere recursos para as ações transversais. Quanto ao CT-Verde Amarelo, por sua natureza ser transversal, não foi feita uma análise específica da aderência a ele que os projetos apoiados por açôes transversais possam ter tido.

Nota: Como cada CT que compõe o FNDCT transfere $50 \%$ de seus recursos às ações transversais, foi considerado o total contratado por cada fundo como equivalente à quantia que este transferira às açôes transversais. 
Como se vê, os dois únicos fundos setoriais integrantes do FNDCT que apareceram como receptores líquidos foram o CT-Biotecnologia e o CT-Transporte - mesmo assim, vale destacar que o primeiro praticamente igualou a quantia que transferiu às ações transversais à que delas recebeu, ${ }^{16}$ enquanto o segundo não contratou nenhum projeto por meio de suas próprias demandas no período. ${ }^{17}$ Afora isso, tem-se o Funttel também como receptor líquido, mas mesmo assim, por se tratar de um fundo setorial à parte, que não compõe o FNDCT, não está sujeito à governança dos demais e, por isso, não transfere recursos às ações transversais. ${ }^{18} \mathrm{O}$ CT-Infraestrutura e o CT-Petro foram os maiores doadores líquidos às ações, em termos absolutos.

Assim, o efeito redistribuição das ações transversais como um todo não só foi relativamente baixo, mas também privilegiou substancialmente apenas o único fundo setorial que não compõe o FNDCT: o Funttel, que, mesmo sem contribuir para o financiamento delas, recebeu um aporte extra das açôes transversais equivalente a mais de $1 / 4$ do valor contratado por esse fundo no mesmo período. No mais, as ações transversais agiram, em certa medida, como substitutas do CT-Transportes, fundo que não obteve êxito na execução de recursos próprios no período, e, no limite, buscaram não enfraquecer o CT-Biotecnologia, para o qual transferiram algum recurso.

\subsection{Para onde vão então os recursos das ações transversais? Uma exploração dos projetos "não-aderentes"}

Os resultados apresentados nas seções 4.1 e 4.2 apontam aderências relativamente baixas, tanto a temas estratégicos da PITCE quanto aos fundos setoriais específicos, dos projetos financiados por ações transversais. Isto leva à refutação das hipóteses do

16 Basta notar que o saldo líquido de cerca de $\mathrm{R} \$ 460$ mil do CT-Biotecnologia frente às ações transversais representa aproximadamente $1 \%$ do total contratado pelo próprio fundo no mesmo período. Uma parcela tão baixa assim pode vir a ser decorrência até mesmo dos próprios filtros usados na identificação dos projetos "aderentes". Uma simples mudança desses filtros poderia ter colocado o CT-Biotecnologia no rol dos "doadores líquidos". Por isso evita-se, no presente trabalho, dizer que esse fundo possa ter sido "privilegiado" pelas ações transversais.

17 A receita do CT-Transportes foi integralmente contingenciada no período, por questões judiciais. Tal fato compromete não apenas as demandas desse fundo, mas também a própria transferência de recursos para as ações transversais. Assim, uma única demanda com ênfase na área de transportes já seria suficiente para gerar uma significativa transferência líquida de recursos das ações transversais para o CT-Transportes. Foi isso que de fato ocorreu: os oito projetos contratados pela Chamada Pública MCTIFINEPIAção Transversal nº 02/2007, cuja temática foi Logística de Transporte, foram responsáveis por $\mathrm{R} \$ 5$ milhões dos $\mathrm{R} \$ 6,12$ milhões que tiveram aderência ao CT-Transportes dentro das ações transversais entre 2005 e 2008. Para mais detalhes sobre as questões judiciais que têm imobilizado o CT-Transportes, ver Guedes e Pompermayer (2010).

18 A respeito da dinâmica específica do Funttel, ver Sousa (2010). 
redirecionamento e da redistribuição. No entanto, uma pergunta paira no ar após a constatação de tais resultados: para quais setores e áreas estariam, então, sendo canalizado o cerca de $1 / 4$ dos recursos dos fundos setoriais que são aplicados por meio de ações transversais?

O caminho para responder a essa pergunta pode estar na identificação dos setores e das áreas mais atendidos pelos projetos que não foram aderentes nem aos temas estratégicos da PITCE, nem aos fundos setoriais. Os resultados desse exercício encontram-se na Tabela 4.

TABELA 4

Setores econômicos e áreas científicas mais contemplados por projetos identificados como "não aderentes" aos temas da PITCE e aos fundos setoriais Brasil - 2005-2008

\begin{tabular}{|c|c|c|c|c|c|}
\hline $\begin{array}{c}\text { Setor } \\
\text { (CNAE) }\end{array}$ & $\begin{array}{c}\mathbf{N}^{0} \text { de } \\
\text { projetos }\end{array}$ & $\begin{array}{c}\text { Valor } \\
\text { contratado } \\
\text { (R\$ } \\
\text { milhões) }\end{array}$ & $\begin{array}{c}\text { Área } \\
\text { científica } \\
(\mathbf{C N P q})\end{array}$ & $\begin{array}{c}\mathbf{N}^{\mathbf{o}} \text { de } \\
\text { projetos }\end{array}$ & $\begin{array}{c}\text { Valor } \\
\text { contratado } \\
\text { (R\$ } \\
\text { milhões) }\end{array}$ \\
\hline Educação & 1922 & 160,95 & $\begin{array}{l}\text { Engenharia } \\
\text { elétrica }\end{array}$ & 126 & 73,67 \\
\hline $\begin{array}{l}\text { Administração } \\
\text { pública, defesa e } \\
\text { seguridade social }\end{array}$ & 1768 & 157,76 & Medicina & 186 & 40,53 \\
\hline $\begin{array}{l}\text { Atividades de } \\
\text { organizações } \\
\text { associativas }\end{array}$ & 179 & 113,20 & $\begin{array}{l}\text { Saúde } \\
\text { coletiva }\end{array}$ & 62 & 38,76 \\
\hline $\begin{array}{l}\text { Pesquisa e } \\
\text { desenvolvimento } \\
\text { científico }\end{array}$ & 314 & 79,23 & $\begin{array}{l}\text { Ciência da } \\
\text { computação }\end{array}$ & 153 & 26,77 \\
\hline $\begin{array}{l}\text { Saúde humana e } \\
\text { serviços sociais }\end{array}$ & 49 & 18,93 & $\begin{array}{l}\text { Engenharia } \\
\text { química }\end{array}$ & 103 & 23,80 \\
\hline
\end{tabular}

Fonte: Ministério da Ciência e Tecnologia - MCT. Elaboração dos autores.

Percebe-se que instituições relacionadas aos setores Educação, Administração Pública, Defesa e Seguridade Social, Atividades de Organizações Associativas, P\&D Científico e Saúde Humana e Serviços Sociais contrataram R \$ 530,1 milhões em projetos de ações transversais que não tiveram aderência nem aos temas estratégicos da PITCE, nem aos fundos setoriais já existentes. Esses cinco setores sozinhos responderam por $61,7 \%$ do total de recursos contratados nos projetos "não-aderentes". Porém, a participação de empresas foi bastante reduzida nos projetos "não-aderentes": 
foram identificadas apenas 220 empresas que contrataram, como executoras ou como intervenientes, $17 \%$ dos R \$ 121,4 milhões alocados a projetos "não-aderentes". ${ }^{19}$

Quanto às áreas científicas, as cinco mais beneficiadas absorveram 29\% dos recursos contratados por tais projetos; acrescentando-se a elas o total que não há informação quanto à área científica, o resultado ultrapassa os 50\% dos recursos contratados. O grande número de projetos sem informação sobre a área científica ocorre tanto entre os aderentes quanto entre os não aderentes - embora não haja, a princípio, motivos para supor que a distribuição das áreas seja consideravelmente diferente para esses projetos em relação à observada para os que informaram sua área de concentração.

De qualquer forma, os projetos de ações transversais têm mostrado acentuada inclinação às engenharias: do total das ações transversais, $\mathrm{R}$ \$ 357,6 milhōes foram contratados por projetos cuja grande área científica predominante foi "Engenharias". Isto representa quase $30 \%$ do total contratado por todos os projetos financiados via ações transversais. Os projetos aqui identificados como "não aderentes" não fugiram dessa tendência, alocando $28,4 \%$ dos recursos contratados a projetos da grande área "Engenharias".

Por fim, vale ressaltar que $50 \%$ dos recursos de projetos não aderentes foram contratados por encomendas. Tendo em vista que as encomendas são o tipo de demanda que mais se aproxima de uma contratação direta e, que, portanto, dariam ao CCFS maiores condições de direcionar os projetos contratados às áreas e setores tidos como mais estratégicos na política industrial, é possível que o processo de formulação das ações transversais esteja se perdendo em atendimento às necessidades de grupos de interesse específicos, em vez de se guiar pelo foco definido na própria política industrial nacional. $\mathrm{O}$ uso das encomendas nas açôes transversais voltará a ser tema de abordagem na seção 6 , após a investigação da hipótese da indução.

\section{Investigando a hipótese da indução}

Antes de prosseguirmos, vale lembrar, mais uma vez, dois fatos.

Primeiro, os recursos destinados às açóes transversais representam, desde que estas foram instituídas, ao menos $50 \%$ de toda a arrecadação vinculada aos fundos

19 Seguindo definição detalhada em Denegri et al. (2009), foram consideradas empresas aquelas instituições cuja natureza jurídica informada na Rais/MTE seja empresa pública e empresa privada, excluídas aquelas cujo setor de atividade econômica seja "administração pública" (CNAE 84), "educação" (CNAE 85) ou "atividades de organizações associativas" (CNAE 94). 
setoriais - sem que, como estes, tenham que seguir diretrizes norteadoras estabelecidas a priori em documento aprovado por comitê competente.

Segundo, o discurso oficial sempre buscou justificar as ações transversais como necessárias para efetivamente direcionar o fomento público a PD\&I aos objetivos e metas estipulados nos planos e políticas nacionais de desenvolvimento, evitando sua dispersão.

Esses dois fatos, aliados à recorrente defesa dos fundos setoriais como instrumento de política, permitem levantar uma terceira hipótese a ser investigada: a de que as ações transversais seriam, no âmbito dos fundos setoriais, o principal meio pelo qual o governo induziria o financiamento privado a PD\&I.

Se assim for, é de se supor que:

- $\quad$ seja maior a participação relativa de empresas nas ações transversais do que nos fundos setoriais propriamente ditos;

- $\quad$ sejam mais robustos os resultados das empresas que acessaram recursos das ações transversais do que daquelas que acessaram recursos dos fundos setoriais propriamente ditos.

A evidência quanto aos resultados apresentados pelas empresas vem sendo investigada em paralelo para o total de recursos alocados a fundos setoriais e ações transversais $^{20}$ - uma avaliação específica para as ações transversais não se viabilizaria no momento por reduzir em muito a amostra de projetos e de empresas envolvidas, dificultando a adequada montagem de um contrafactual ao "experimento das ações transversais". Com isso, no presente trabalho, será examinada apenas a participação relativa das empresas.

Esse exame revela que $29,9 \%$ dos projetos oriundos de ações transversais têm participação de empresas, enquanto nos projetos apoiados pelos fundos setoriais propriamente ditos (isto é, sem as ações transversais), esse percentual, no mesmo período (2004-2008), é de 27,7\%.

Trata-se de uma diferença pequena, mas vale destacar que, dos projetos apoiados por ações transversais que tiveram participação de empresas, 76,9\% apresentaram ao menos uma delas como executora. Quando são considerados apenas os projetos dos fundos setoriais propriamente ditos, essa proporção cai para 70,5\%. Este dado indica uma participação levemente mais expressiva das empresas que participam de projetos de ações transversais do que das que adentram naqueles apoiados por fundos setoriais propriamente ditos. 
Assim, ao menos no que tange à participação de empresas, constata-se que, em certa medida, algum avanço tem sido obtido com as ações transversais quanto à participação relativa das empresas nos projetos financiados. Essa afirmação merece, porém, algumas ressalvas e contextualizações.

Se, por um lado, o envolvimento de empresas pode ser observado em termos de quantidade relativa de projetos em que se fazem presentes (em particular em quantos projetos esse envolvimento se estende à sua execução direta), por outro, a repercussão desse envolvimento nas atividades de P\&D das empresas poderia ter como indicador o montante de valor contratado via açóes transversais em comparação com o que fora observado para os fundos setoriais específicos. Ao se fazer isso, verifica-se que, nos projetos com participação de empresas, o volume de recursos contratados foi bem inferior naqueles financiados por ações transversais do que nos provenientes de demandas dos fundos específicos.

Em números, os projetos com participação de empresas movimentaram, em valores de 2008, R\$ 721,6 milhões operados no período em análise pelos comitês gestores dos 16 fundos setoriais e $\mathrm{R} \$ 211,8$ milhões dos recursos contratados pelas ações transversais aprovadas pelo CCFS. Ou seja, no que tange a projetos com participação de empresas, para cada R \$ 1 aplicado pelas ações transversais, foram invertidos R \$2,41 pelos fundos setoriais propriamente ditos. Essa proporção fornece uma boa ideia do grau de pulverização dos recursos nas açôes transversais, até porque o volume total investido por elas e pelos fundos é quase paritário (dado que as ações transversais utilizam um piso de $50 \%$ das receitas de cada fundo setorial).

A pulverização revela-se ainda mais forte quando se considera que, em termos de número de projetos, tal como visto anteriormente, o envolvimento de empresas chega a ser um pouco maior nas ações transversais. Os projetos das ações transversais que envolvem empresas são menores, em termos de recursos, do que aqueles dos fundos setoriais. $\mathrm{O}$ valor contratado médio por projeto com empresas equivale a $\mathrm{R} \$$ 202.284,69 nas açóes transversais, contra R \$ 381.402,32 nos fundos setoriais. Por outro lado, as empresas engajadas em projetos de ações transversais são maiores do que aquelas que participam de projetos financiados pelos CTs, ao menos em termos de número de empregados. Contrariando a expectativa de que projetos menores implicariam empresas menores, aquelas engajadas em projetos de ações transversais empregam, em média, 1.161 pessoas (21\% têm mais de 1.000 funcionários), enquanto as que participam de projetos financiados pelos CTs empregam, em média, 1.024 pessoas (15\% delas tinham mais de 1.000 funcionários). O fato de as empresas 
envolvidas com ações transversais terem em média mais funcionários pode refletir, em verdade, maior intensidade em trabalho do que em capital.

Tanto em um caso como em outro, o setor de atividade econômica mais recorrente das empresas envolvidas com projetos foi o de fabricação de equipamentos de informática, produtos eletrônicos e óticos. Em menor grau, serviços relacionados à tecnologia da informação e fabricação de máquinas e equipamentos também foram setores bastante recorrentes. Produtos alimentícios e farmoquímicos e farmacêuticos completaram os cinco setores que tiveram maior destaque nas açóes transversais, ao passo que, para os fundos setoriais, essa lista foi completada pelos setores de fabricantes de produtos químicos e de produtos de minerais não metálicos.

Por fim, buscou-se comparar a participação de empresas em projetos de açōes transversais e dos fundos setoriais, investigando-se o perfil daquelas que tenham sido executoras de projetos grandes, assim considerados, para fins de análise, aqueles cujo valor contratado tenha superado R $\$ 1$ milhão. Apenas oito empresas foram executoras de projetos financiados por açôes transversais acima desse valor. Já os fundos setoriais específicos foram mais capazes de mobilizar empresas na execução de projetos de maior vulto: 119 firmas figuraram como executoras de projetos por eles contratados acima de R 1 milhão.

Em termos de número de empregados, essas oito empresas das ações transversais eram, em média, maiores do que as 119 dos fundos setoriais: 2.522 contra 854 . Em verdade, metade das 119 empresas executoras de projetos grandes dos CTs tinha até 50 funcionários. Distribuíram-se essas 119 nos setores mais diversos, com maior concentração em fabricação de equipamentos de informática, produtos eletrônicos e óticos (28), serviços relacionados à tecnologia da informação (14), pesquisa e desenvolvimento científico (9) e fabricação de produtos farmoquímicos e farmacêuticos (7). Já entre as empresas executoras de projetos grandes de ações transversais, os setores de atividade econômica que aparecem são pesquisa e desenvolvimento científico (5), comércio varejista (1) e atividades de atenção à saúde humana (1).

Dessa forma, tudo o que se pode dizer em relação à hipótese 3 é que as açōes transversais conseguiram atrair maior participação relativa de empresas. Tal envolvimento, entretanto, se deu de forma mais pulverizada do que nos fundos setoriais, em projetos de menor vulto. Portanto, os dados disponíveis não permitem fazer quaisquer ilações sobre eventuais avanços na indução ao financiamento privado à PD\&I. 


\section{Algo mais a destacar: o acentuado uso de encomendas}

Por intermédio das ações transversais, no período entre julho de 2004 e setembro de 2008, foram contratados $R \$ 1,31$ bilhão ${ }^{21}$ na forma de 5.854 projetos. Esses recursos vêm financiando o custeio de passagens, diárias, material de consumo, serviços de terceiros, investimento em obras civis, instalaçôes, equipamentos e bolsas.

Os projetos, tanto de açôes transversais quanto aqueles dentro do escopo de fundos específicos, são contratados a partir de três diferentes instrumentos de seleção e/ou contratação pública:

- chamadas públicas: selecionam as propostas que melhor respondam às características especificadas na convocatória. São utilizadas quando o CCFS (no caso das ações transversais) ou os comitês gestores (no caso de cada fundo setorial) definem uma ou mais áreas temáticas ou setores estratégicos de interesse dos programas de pesquisa científica e tecnológica cooperativa entre universidades, centros de pesquisa e setor produtivo;

- cartas-convite: modalidade de concorrência pública utilizada quando o ente público deseja restringir o número de concorrentes àquelas instituiçôes de reconhecida capacidade técnica para atender ao objeto demandado. No âmbito das ações transversais e dos fundos setoriais, instituições são convidadas por este instrumento a submeterem propostas de projetos de pesquisa aplicada, desenvolvimento experimental e/ou engenharia não rotineira, com vistas à geração de produtos ou processos produtivos inovadores ou que contribuam para a superação de obstáculos ou acarretem inovações estratégicas para o setor considerado. As propostas apresentadas passam por uma pré-qualificação, para então ocorrer a avaliação acerca de qual (ou quais) será (serão) contratada(s);

- encomendas: instrumento utilizado em situaçôes de urgência ou cuja especificidade enseje a convocação de determinada instituição ou pessoa de reconhecida experiência e capacidade técnica para o fim demandado. Quando assim for, o CCFS ou o comitê gestor do fundo setorial poderá encomendar o desenvolvimento de um projeto diretamente a uma instituição específica, de reconhecida competência. Também pode ocorrer por encomenda a realização de estudos ou eventos estratégicos.

21 Tal como já mencionado, quantia aproximada a partir de valores anuais deflacionados pelo IPCA (ano-base 2008). 
A Tabela 5 mostra a distribuição, por tipo de demanda, dos projetos e dos valores contratados via açôes transversais no período estudado. Percebe-se que, embora $90,8 \%$ dos projetos tenham sido contratados por meio de chamadas públicas, esta modalidade corresponde a $44,9 \%$ do valor total contratado. ${ }^{22}$ As encomendas, por sua vez, foram utilizadas para contratar $44,85 \%$ dos recursos, aplicados em apenas $8 \%$ dos 5.854 projetos. Por fim, a modalidade carta-convite aplicou um montante bem menor de recursos (6,3\% do total) a um quantitativo quase residual de projetos $(1,2 \%)$, apesar de estes apresentarem valor médio bastante próximo ao dos projetos contratados por encomendas.

TABELA 5

Número de projetos e valor contratado, segundo tipo de demanda Brasil - 2004-2008

\begin{tabular}{l|r|r|c|c|c}
\hline Tipo de demanda & $\begin{array}{c}\mathbf{N}^{\mathbf{0}} \text { de } \\
\text { projetos }\end{array}$ & $\%$ & $\begin{array}{c}\text { Valor } \\
\text { contratado } \\
\text { (em R\$ mil) }\end{array}$ & $\%$ & $\begin{array}{c}\text { Valor médio } \\
\text { por projeto } \\
\text { (em R\$ mil) }\end{array}$ \\
\hline Carta-convite & 69 & 1,2 & $83.110,82$ & 6,3 & $1.204,50$ \\
Chamada pública & 5314 & 90,8 & $587.729,62$ & 44,9 & 110,60 \\
Encomenda & 471 & 8,0 & $638.797,90$ & 48,8 & $1.356,26$ \\
\hline
\end{tabular}

Fonte: Ministério da Ciência e Tecnologia - MCT. Elaboração dos autores.

Dos 20 maiores projetos contratados pelas ações transversais, em termos de recursos, 17 foram contratados a partir de encomendas oriundas da Finep e os outros três decorreram de duas cartas-convite, também da Finep, e uma chamada pública do CNPq. Criando-se um recorte dos projetos com valor contratado igual ou superior a $\mathrm{R} \$ 1$ milhão (270 projetos), percebe-se que 58,5\% destes foram originados de encomendas, 32,6\% de chamadas públicas e 8,9\% de cartas-convite. Quase a totalidade $(96,7 \%)$ desses 270 projetos tem como agência financiadora a Finep.

22 Parte da dispersão dos recursos nas chamadas públicas deve-se à existência dos chamados editais universais. No período analisado, houve apenas um desses editais. Porém, ele sozinho contratou 4.049 dos 5.854 projetos do período, nos quais injetou aproximadamente $R \$ 100,4$ milhões até setembro de 2008 . Com faixas com teto máximo de $R \$$ 20 mil, $R \$ 50$ mil ou de $R \$ 150$ mil por projeto, esse edital, aberto a qualquer área, acabou por tornar-se a principal fonte de apoio a projetos de pequena magnitude e de áreas tradicionalmente de menor densidade tecnológica, como Ciências Humanas, Letras e Artes. Sem contabilizar os projetos contratados a partir do edital universal, as chamadas públicas passam a representar $70,1 \%$ do número de projetos e $40,3 \%$ dos recursos contratados. O valor médio de seus projetos, contudo, permanece bastante inferior ao daqueles financiados por encomendas e cartas-convite: $R \$$ 385,26 mil. 
A elevada proporção de recursos aplicados em projetos apoiados por meio de encomendas, bem como o alto valor médio contratado por esses projetos (aproximadamente R \$ 1,36 milhão), faz desse instrumento uma fonte em potencial das estratégias de fato do governo, no que tange ao fomento à PD\&I via fundos setoriais. Afinal, dadas as especificidades que as aproximam de contratações diretas, as encomendas são um instrumento que permite direcionar, com boa dose de precisão, objeto, escopo, objetivos e metas dos projetos que financia - e que consumiram cerca de $25 \%^{23}$ do total de recursos disponíveis aos fundos setoriais entre julho de 2004 e setembro de 2008.

Dessa forma, as encomendas de ações transversais têm o potencial de alavancar a PD\&I em áreas e setores que sejam estratégicos ao governo - sejam essas áreas e setores identificados em documentos oficiais, ou não.

Assim, merecem especial atenção os 471 projetos contratados por encomenda de ações transversais no período em análise. ${ }^{24}$ Por conta disto, os dados concernentes às açôes transversais são apresentados a seguir também com recortes quanto ao tipo de demanda - o que advém de encomendas foi tratado separadamente ao que fora contratado a partir de chamadas públicas e de cartas-convite. A distribuição do valor contratado é mostrada no Gráfico 2, segundo categorias, e no Gráfico 3, segundo grandes áreas. A Tabela 6, por sua vez, ranqueia, em termos de valor contratado, os setores mais beneficiados.

A análise conjunta dos Gráficos 2 e 3 e da Tabela 6 sugere que as encomendas de ações transversais vêm contribuindo para o fortalecimento da infraestrutura de pesquisa científica e tecnológica e para o fomento à PD\&I em áreas estratégicas. Além disso, elas viabilizaram, em certa medida, tecnologias para inovação nas empresas. Seguindo a tendência observada nos recortes explorados nas seções precedentes, as engenharias constituem a grande área mais contemplada por açôes transversais contratadas por esse tipo de demanda, embora a expressiva quantidade de projetos sem informação disponível nesse quesito possa estar subdimensionando a participação de outras áreas nos projetos apoiados (ou mesmo das próprias engenharias).

Ademais, a pesquisa e o desenvolvimento cientifico aparecem como principal setor de atividade apoiado, com quase três vezes mais recursos do que os projetos

23 48,8\% dos recursos das ações transversais, que, por sua vez, aplicam um mínimo de $50 \%$ das receitas vinculadas a cada um dos fundos setoriais.

24 De acordo com Rezende (2006, p. 351), "As encomendas são destinadas a projetos de pesquisa e desenvolvimento de produtos, solução de desafios tecnológicos prioritários ou pesquisa em temas de fronteira da ciência". 
com foco na extração de petróleo e gás natural (2o colocado). Este dado parece indicar uma inclinação das encomendas de ação transversal no sentido de apoiar a P\&D experimental, ${ }^{25}$ mormente associada ao desenvolvimento de novos produtos e processos. Este é um dado potencialmente positivo, caso em tais projetos esteja ocorrendo um desdobramento desejável: a integração universidade-empresa.

\section{GRÁFICO 2}

Distribuição dos recursos a fundos setoriais, segundo categorias

Brasil - 2004-2008

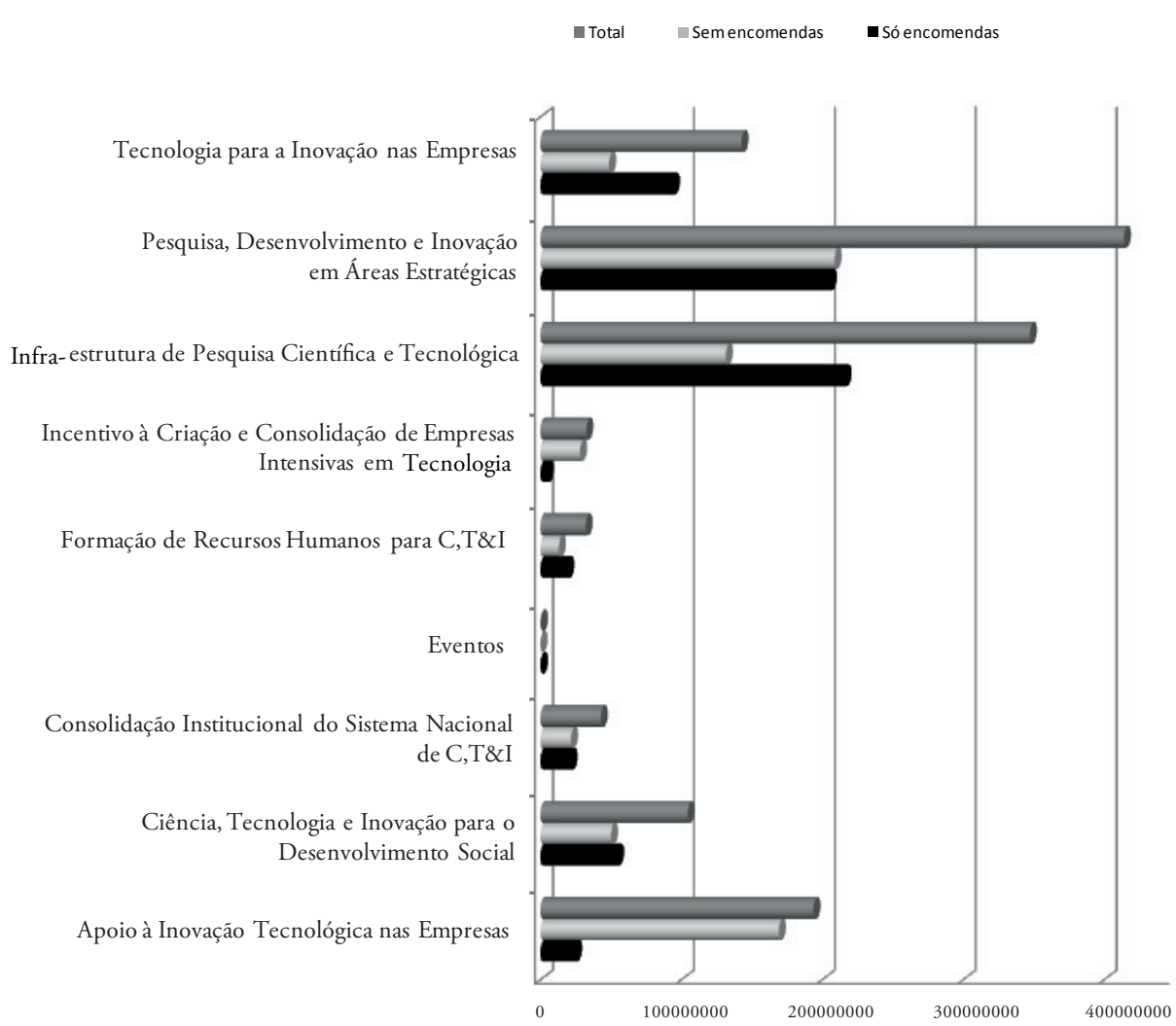

Fonte: Ministério da Ciência e Tecnologia - MCT. Elaboração dos autores.

25 A atividade econômica pesquisa e desenvolvimento científico subdivide-se, na Classificação Nacional de Atividades Econômicas (CNAE) em vigor, em $P \& D$ experimental em ciências físicas e naturais e em $P \& D$ experimental em ciências sociais. 


\section{GRÁFICO 3}

Distribuição dos recursos a fundos setoriais, segundo grandes áreas

$$
\text { Brasil - 2004-2008 }
$$

- Total $\quad$ Semencomendas

- Só encomendas

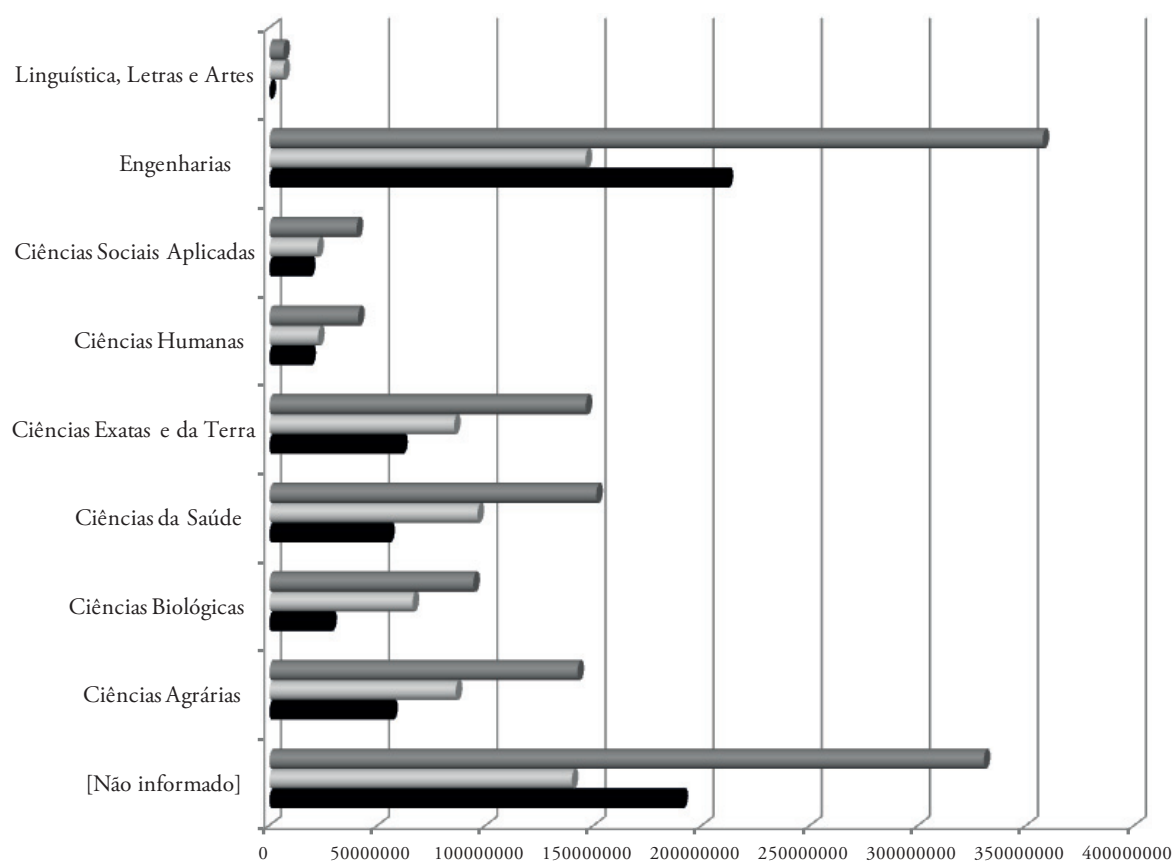

Fonte: Ministério da Ciência e Tecnologia - MCT. Elaboração dos autores.

É possível supor, todavia, que, no caso específico das encomendas de ações transversais, eventuais integrações universidade-empresa ocorram em menor escala, ou ao menos não se verifiquem de maneira imediata. Embora apenas uma hipótese, tal assertiva decorre do fato de que, entre as ações transversais, os projetos contratados via encomenda apresentam participação relativa de empresas menor do que aqueles selecionados por chamadas públicas - tal qual mostra o Gráfico 4.

O Gráfico 4 poderia suscitar um aparente paradoxo. Conforme hipótese anterior aqui desenvolvida, as encomendas de ações transversais teriam o potencial de alavancar a PD\&I em áreas e setores que sejam estratégicos ao governo. Porém, a participação de empresas mostra-se menor em projetos contratados por esse tipo de demanda do que por chamadas públicas. Com isso, dever-se-ia supor que as encomendas 
de açóes transversais estariam destoando da lógica dos fundos setoriais, isto é, em vez de representarem um eficaz instrumento de fomento público ao financiamento privado à $P D \& I$, estariam elas, em verdade, financiando tão somente a $P \& D$ em universidades e institutos de pesquisa?

\section{TABELA 6}

Principais setores financiados, ranqueados pelo montante de valor contratado por encomendas de ações transversais

Brasil - 2004-2008

\begin{tabular}{|c|c|c|c|c|c|}
\hline Posição & Setor & $\begin{array}{c}\mathrm{N}^{\circ} \mathrm{de} \\
\text { projetos }\end{array}$ & \begin{tabular}{|c|} 
Valor \\
contratado \\
(R\$ milhões)
\end{tabular} & $\begin{array}{l}\text { Posição no } \\
\text { ranking } \\
\text { de ações } \\
\text { transversais } \\
\text { sem } \\
\text { encomendas }\end{array}$ & $\begin{array}{l}\text { Posição no } \\
\text { ranking } \\
\text { de fundos } \\
\text { setoriais } \\
\text { sem ações } \\
\text { transversais }\end{array}$ \\
\hline 1 & $\begin{array}{l}\text { Pesquisa e } \\
\text { desenvolvimento } \\
\text { científico }\end{array}$ & 48 & 43,87 & 2 & 2 \\
\hline 2 & $\begin{array}{l}\text { Extração de petróleo } \\
\text { e gás natural }\end{array}$ & 36 & 16,19 & 3 & 4 \\
\hline 3 & $\begin{array}{l}\text { Serviços para } \\
\text { edifícios e atividades } \\
\text { paisagísticas }\end{array}$ & 8 & 8,30 & 9 & 8 \\
\hline 4 & $\begin{array}{l}\text { Fabricação de } \\
\text { produtos alimentícios }\end{array}$ & 8 & 4,65 & (1) & (1) \\
\hline 5 & $\begin{array}{l}\text { Eletricidade, gás e } \\
\text { outras utilidades }\end{array}$ & 2 & 3,55 & (1) & (1) \\
\hline
\end{tabular}

Fonte: Ministério da Ciência e Tecnologia - MCT. Elaboração dos autores.

(1) Não aparece entre os dez setores mais beneficiados.

Nota: Cada projeto pode estar relacionado a várias empresas, que, por sua vez, estão relacionadas a várias CNAEs. Por isso, há sobreposiçāo de contagem do número de projetos por CNAE (um mesmo projeto pode estar relacionado a várias CNAEs e, portanto, é contabilizado em todas as CNAEs que ele está relacionado). Seguindo definição detalhada em De Negri et al.(2009), foram considerados apenas os projetos relacionados a instituiçōes classificadas, segundo a natureza jurídica informada na Rais/MTE, como empresas públicas e empresas privadas, excluídas aquelas cujo setor de atividade econômica seja "administração pública" (CNAE 84), "educação" (CNAE 85) ou "atividades de organizaçôes associativas" (CNAE 94).

De fato, um exame das mais de 120 instituições executoras dos projetos apoiados por encomenda de açóes transversais revela que a quase totalidade delas corresponde a institutos de pesquisa, universidades e fundações a elas atreladas. No entanto, isto não significa que apenas o que é desenvolvido por e nessas instituições é que é estratégico. As encomendas relacionam-se, em geral, a estudos específicos e, dado o expressivo contingente de recursos que destinam à infraestrutura de pesquisa científica e tecnológica (ver Gráfico 2), criam ou reforçam as condições para o 
desenvolvimento das áreas e dos setores estratégicos. Até onde é possível perceber com os dados disponíveis, engenharias (ver Gráfico 3) e pesquisa e desenvolvimento cientifico (ver Tabela 6) seriam, respectivamente, a área e o setor mais estratégicos no período estudado.

\section{GRÁFICO 4 \\ Distribuição do valor contratado de projetos com participação de empresas e do número de empresas beneficiadas, segundo tipo de demanda Brasil - 2004-2008}

Valor contratado com participação de empresas

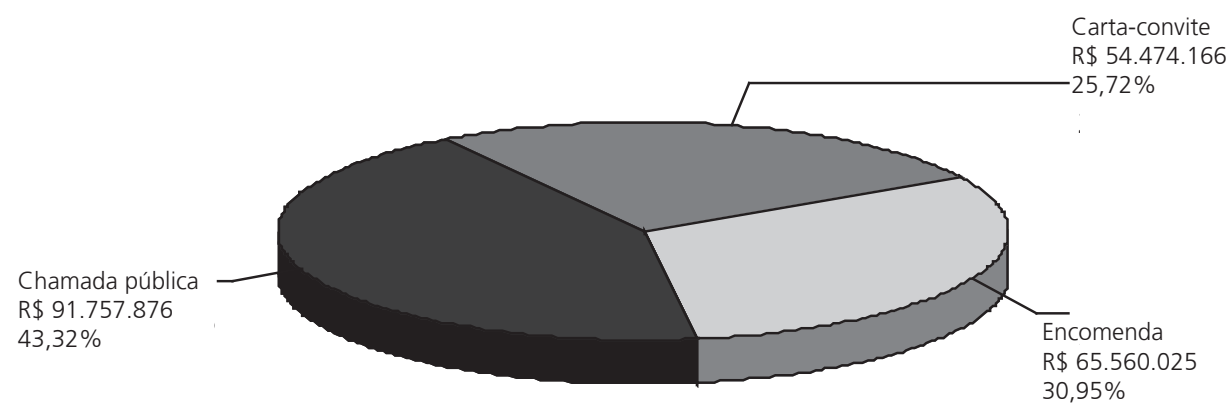

Empresas beneficiadas

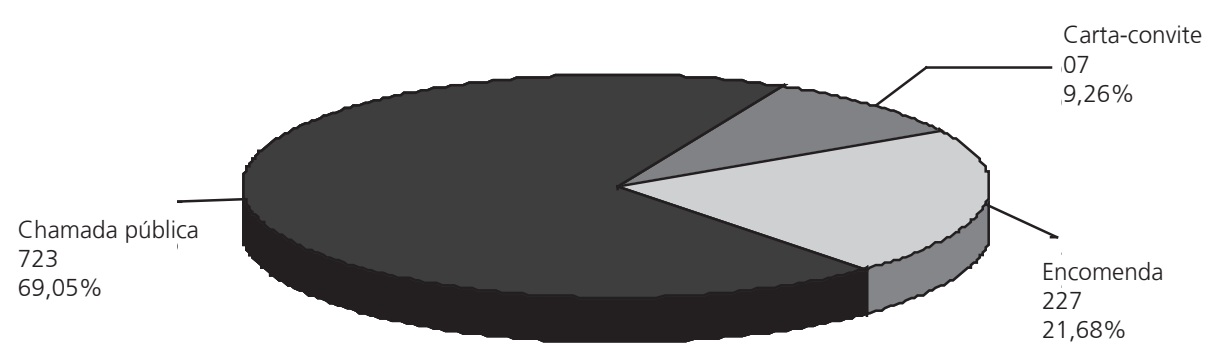

Fonte: Ministério da Ciência e Tecnologia - MCT. Elaboração dos autores.

Portanto, as encomendas de açōes transversais apontam para o fortalecimento da infraestrutura científica e tecnológica e para o fomento à PD\&I em áreas estratégicas, particularmente engenharias. 


\section{Considerações finais, conclusões e implicações de política}

As ações transversais representam uma inovação à dinâmica dos fundos setoriais de Ciência e Tecnologia. Introduzidas no segundo semestre de 2004, elas merecem atenção especial por dois motivos: realocam ao menos metade das receitas não contingenciadas dos fundos setoriais que compõem o FNDCT; e, por não estarem atreladas a diretrizes e objetivos preestabelecidos, podem tanto conferir maior organicidade, uniformidade e coordenação ao financiamento público à inovação, quanto dispersar os recursos aplicados sem seguir um padrão consistente com as políticas em voga.

$\mathrm{Na}$ tentativa de responder à pergunta Qual tem sido o papel das açôes transversais dentro da politica de financiamento público à inovação no Brasil?, o presente trabalho buscou construir uma estratégia de análise que superasse a contento a ausência de documentos oficiais formais, estabelecendo a priori uma orientação quanto ao escopo a ser adotado pelas ações transversais. Recorrendo a manifestações públicas das autoridades competentes, à legislação aplicável ao FNDCT, aos documentos de políticas pertinentes e a análises precedentes disponíveis, levantaram-se três hipóteses, cuja investigação permitiria delinear uma possível resposta à pergunta-problema.

Duas das hipóteses investigadas remetiam a possíveis caminhos complementares que as ações transversais poderiam, em tese, ter tomado: um deles seria o do redirecionamento dos recursos dos fundos setoriais a temas estratégicos da política industrial e o outro o da redistribuição desses recursos entre os CTs existentes. Já a terceira hipótese buscava investigar se teriam sido as açôes transversais bem-sucedidas na tarefa de indução do financiamento privado à pesquisa, ao desenvolvimento e à inovação no Brasil.

As hipóteses do redirecionamento e da redistribuição foram testadas a partir de análises de aderência aos temas, respectivamente, da PITCE e dos próprios CTs. Os resultados revelados não indicavam tendência nem ao redirecionamento nem à redistribuição dos recursos dos fundos setoriais após a interveniência das ações transversais - embora áreas tradicionalmente intensivas em tecnologia, como engenharias e saúde, tenham tido também destaque entre os projetos classificados como "não aderentes". A hipótese da indução tampouco pôde ser convictamente aceita a partir dos dados disponíveis. Ao melhor, pode-se dizer que as ações transversais conseguiram atrair maior participação relativa de empresas, ainda que esse maior envolvimento em termos de número de projetos tenha sido pulverizado em projetos de menor vulto do que os apoiados pelos CTs. 
Complementou-se a análise proposta com um adendo acerca da utilização das encomendas para a implementação de ações transversais. Responsável por quase metade da aplicação dos recursos contratados por intermédio de ações transversais no período investigado, esse tipo de demanda, a que mais se aproxima de contratação direta entre os instrumentos convocatórios possíveis, parece ter privilegiado o fortalecimento da infraestrutura científica e tecnológica e o fomento à PD\&I em áreas estratégicas, particularmente engenharias, além de terem viabilizado, em certa medida, tecnologias para inovação nas empresas. Por outro lado, as encomendas mostraramse quase ausentes no apoio à inovação tecnológica nas empresas e no incentivo à criação e consolidação de empresas intensivas em tecnologia. Ademais, projetos por elas financiados apresentaram nível de participação de empresas bastante inferior ao verificado para os outros tipos de demanda (chamadas públicas e cartas-convite).

Em vista do exposto, conclui-se que as açôes transversais não têm sido capazes de desempenhar o papel para o qual teriam sido criadas - o de dar maior organicidade, uniformidade e coordenação à governança dos fundos setoriais. Em tese, esse papel deveria (e, como mostrado, não parece ter sido) se materializar: no redirecionamento e/ou na redistribuição dos recursos aplicados pelos fundos setoriais, de forma a utilizá-los para fortalecer temáticas e setores estratégicos para a política de desenvolvimento nacional; e na indução do financiamento privado à PD\&I.

Em face do insuficiente resultado observado em ambos os sentidos, far-se-ia necessário que as temáticas das demandas de ações transversais passassem a ser pautadas pelas medidas da Política de Desenvolvimento Produtivo (PDP) a cargo das agências executoras dos fundos (Finep e $\mathrm{CNPq}$ ) - o que não ocorreu no período em que a PITCE vigorava - e, ainda, que as demandas lançadas fossem capazes de estimular e facilitar de forma mais efetiva a integração universidade-empresa, o que poderia ter sido puxado (e não tem sido) pelas encomendas, por serem estas o tipo de convocatória com o qual o formulador de política tem maiores condições de direcionar o objeto, o escopo, os objetivos e as metas das iniciativas em que injeta recursos públicos. 


\section{Referências bibliográficas}

ARAÚJO, B. C. et al. Impacts of the Brazilian science and technology funds on the industrial firm's $R \& D$ inputs and outputs. Tartu, Estônia: Maastricht University e United Nations University (UNU-MERIT), 2010. Mimeo [Apres. Fourth Conference on Micro Evidence on Innovation in Developing Economies - MEIDE 2010, Tartu, Estônia, 27-28 mai. 2010].

CÉSAR JR., S. Fronteira tecnológica e escassez de recursos: uma análise da nanotecnologia no Brasil. Radar - Tecnologia, Produção e Comércio Exterior, Brasília (DF), n. 9, p. 1926, ago. 2010.

DE NEGRI, F. et al. Perfil das empresas integradas ao sistema federal de CT\&I no Brasil e aos fundos setoriais: uma análise exploratória. Brasília: Ipea, 2009.

DE NEGRI, J. A.; LEMOS, M. B. Avaliação das politicas de incentivo à P\&D e inovação tecnológica no Brasil. Brasília: Ipea, 2009. Disponível em: <www.ipea.gov.br>. Acesso em: 8 jan. 2010.

FERRARI, A. F. O Fundo Nacional de Desenvolvimento Científico e Tecnológico - FNDCT e a Financiadora de Estudos e Projetos - Finep. Revista Brasileira de Inovação, v. 1, n. 1, p. 151-188, jan.-jun. 2002.

GUEDES, E. P.; POMPERMAYER, F. M. O CT-Transporte e a necessidade de financiamento a P\&D em transportes e logistica. Brasília: Ipea, 2010.

LONGO, W. P. E.; DERENUSSON, M. FNDCT, 40 anos. Revista Brasileira de Inovação, v. 8, n. 2, p. 515-533, jul.-dez. 2009.

MELO, L. M. Financiamento à inovação no Brasil: análise da aplicação dos recursos do Fundo Nacional de Desenvolvimento Científico e Tecnológico (FNDCT) e da Financiadora de Estudos e Projetos (Finep) de 1967 a 2006. Revista Brasileira de Inovação, v. 8, n. 1, p. 87-120, jan.-jun. 2009.

PACHECO, C. A. Estratégia para fundos setoriais. Revista Brasileira de Inovação, v. 6, n. 1, p. 191-223, jan.-jun. 2007.

PEREIRA, N. M.; HASEGAWA, M.; AZEVEDO, A. M. D. Relatório de aderência dos fundos setoriais. Brasília: CGEE, 2006.

REZENDE, S. M. Consolidação dos instrumentos da política de Ciência, Tecnologia e Inovação. In: VELLOSO, J. P. R. (Coord.). Por que o Brasil não é um país de alto crescimento? Rio de Janeiro: José Olympo Editora, 2006, p. 339-361. 
SOUSA, R. A. F. de. Avaliação da política de incentivo à inovação para o setor de telecomunicaçôes brasileiro. Brasília: Ipea, 2010.

VIEIRA FILHO, J. E. R. Políticas públicas de inovação no setor agropecuário: uma avaliação dos fundos setoriais. Brasília: Ipea, 2010.

ENDEREÇOS PARA CORRESPONDENCIA:

Paulo A. Meyer M. Nascimento - paulo.nascimento@ipea.gov.br SBS Qd. 1, bloco J, Edf. BNDES/Ipea, $11^{\circ}$ andar 70076-900 - Brasília/ DF

João Maria de Oliveira - joao.oliveira@ipea.gov.br SBS Qd. 1, bloco J, Edf. BNDES/Ipea, $11^{\circ}$ andar 70076-900 Brasília/ DF 